\title{
EDUCAR PELA PESQUISA: UMA EXPERIÊNCIA INVESTIGATIVA NO ENSINO E APRENDIZAGEM DE FÍSICA
}

\author{
Suzana Maria Coelho \\ Rita Mara Bueno Timm \\ Juliana Mariani Santos \\ Grupo de Pesquisa em Didática das Ciências - GPDC \\ Faculdade de Física - PUCRS \\ Porto Alegre - RS
}

\section{Resumo}

O presente artigo ${ }^{I}$ apresenta uma experiência de introdução à prática da pesquisa realizada na disciplina de Didática das Ciências, em um curso de mestrado, com ênfase na formação de professores-pesquisadores. Trata-se de um projeto com abordagem metodológica qualitativa, aplicado a alunos do Ensino Fundamental e do Ensino Médio, no qual se utilizou a técnica da observação participante, durante atividades experimentais no campo da eletricidade. Os resultados mostram como foi vivenciada a formação pela pesquisa que implicou atividades de elaboração de projeto de pesquisa, de análise e interpretação de dados e culminou com a elaboração coletiva deste trabalho. Percebe-se a relevância atribuída a esse tipo de formação, com consequências promissoras na docência e em atividades de pesquisa. Nesse processo, considerou-se a importância dos co-

\footnotetext{
${ }^{+}$Education through research: an investigative experiment in Physics teaching and learning

* Recebido: março de 2010.

Aceito: maio de 2010.

Artigo elaborado com base em projeto realizado na disciplina Didática das Ciências, por aluna do Curso de Mestrado do Programa de Pós-Graduação em Educação em Ciências e Matemática da Faculdade de Física da Pontifícia Universidade Católica do Rio Grande do Sul de Porto Alegre, e em trabalho apresentado no XVIII Simpósio Nacional de Ensino de Física, no período de 26 a 30 de janeiro de 2009, Vitória, ES.
} 
nhecimentos prévios dos alunos, visando a melhoria da prática pedagógica do professor-pesquisador e a maiores possibilidades de aprendizagem para o aluno.

Palavras-chave: Educar pela pesquisa; Didática das Ciências; ensino e aprendizagem de Física.

\begin{abstract}
The article ${ }^{2}$ presents an introduction to research experiment carried out in the Science Teaching Methods course part of a Masters Degree program emphasizing teacher-researcher education. The experiment used a qualitative methodological approach, applied to Elementary and High Schools where participant observation technique was used during the experimental activities in the field of electricity. The results show how the education through research was experienced, which comprised activities in research project elaboration, data analyses and interpretation, and culminating with the collective elaboration of the present paper. The relevance given to this kind of education is noticeable, with promising consequences on teaching and research activities. In this process the importance of the pupils' background knowledge was taken into account, having in mind the improvement of the teacher/researcher pedagogical practice as well as pupil learning possibilities.
\end{abstract}

Keywords: Education through research; Science Teaching Methods; Physics teaching and learning.

\title{
I. Introdução
}

A prática da pesquisa apresenta-se como uma modalidade na educação científica que possibilita a construção de um olhar crítico para tomadas de decisões mais acertadas pelo professor, auxiliando-o a conhecer-se como profissional, a

\footnotetext{
${ }^{2}$ Article written based on the Project carried out by a student in the Masters Degree Program in Science and Mathematics Education of the Science Methods course at the School of Physics of the Pontificia Universidade Católica do Rio Grande do Sul, and a paper presented at the XVIII Physics Teaching National Symposium , January 26-30, 2009, Vitória, ES, Brazil.
} 
conhecer o aluno e suas necessidades, passando, assim, a entender melhor a quem ensina.

Segundo Coelho (2000, 2005, 2008), Demo (2005), Moraes (2004) e Astolfi $(1988,1998,2001)$, o professor, ao pesquisar sua prática, adquire novos instrumentos para aperfeiçoá-la e tornar a aprendizagem um processo significativo para o aluno.

Ao impregnar-se da pesquisa, o professor tem a oportunidade de tornar essa atividade uma prática quotidiana, vivenciada no seu planejamento e na sua metodologia. Por isso, a educação pela pesquisa nos cursos de formação inicial e continuada de professores de Ciências é uma opção a ser considerada. Conforme Leite (2004),

Para que o professor organize seu ensino, segundo orientações construtivas, é indispensável que se seja não um pesquisador profissional, mas um profissional pesquisador. Do contrário, dificilmente conseguirá ser um orientador de aprendizagem numa perspectiva de construção de conhecimentos científicos (p. 68).

O projeto apresentado neste artigo integrou o planejamento programático das disciplinas de Didática das Ciências, no âmbito de um Programa de Mestrado em Educação em Ciências cujo princípio norteador é o educar pela pesquisa, e de Metodologia do Ensino de Física, do curso de Licenciatura em Física, em nível de Graduação. A partir do estudo de autores europeus, sobretudo franceses, como Astolfi (1998, 2000, 2001), Bachelard (1996), Giordan (1996, 1989), Pérez (1983) e Halbwachs (1975), foram introduzidos conhecimentos sobre metodologias e práticas em sala de aula, alicerçadas em pesquisas e teorias sobre aprendizagem, objetivo-obstáculo (ASTOLFI, 1988), resolução de problemas (PÉREZ, 1988), transposição didática (HALBWACHS, 1975; ARCÁ, 1989; PAIS, 2001), contrato didático, conhecimento prévio (GIORDAN, 1989), estratégias de ensino (COELHO, 2000) e o papel das atividades experimentais (SÉRÉ, 2003), as quais serviram de fundamentação teórica na construção e aplicação do projeto. A pesquisa foi realizada em várias etapas no decorrer de um semestre, compreendendo a elaboração do projeto, a coleta de dados, sua análise e redação do relatório final, promovendo, desse modo, uma constante reflexão sobre a importância de cada um desses processos na formação de um professor-pesquisador.

O desenvolvimento da investigação, evidenciando as tomadas de decisão do pesquisador e os resultados obtidos, será explanado ao longo do artigo. Os resultados apresentados são referentes apenas às análises realizadas pela mestranda a respeito do papel do conhecimento prévio do aluno na construção do conhecimento 
científico. Outros aspectos, analisados pelos estudantes graduandos em Física, serão objeto de um futuro trabalho.

\section{II.1 Justificando e descrevendo a proposta}

Na pesquisa Investigando as Implicações dos Conhecimentos Prévios na Aprendizagem de noções de Eletricidade, realizada com alunos do Ensino Fundamental e do Ensino Médio, investigou-se como os sujeitos constroem seus conceitos científicos a partir de seus conhecimentos prévios e quais os papéis desses conhecimentos em sua aprendizagem. Buscou-se a ação e a reflexão sobre um tema em Física experimental, desenvolvendo-se atividades com montagem e exploração de experimentos no campo da eletricidade.

Adotou-se como referência epistemológica pressupostos construtivistas, por entender-se que o aluno é autor de sua aprendizagem e constrói seus conceitos tomando por base suas concepções prévias e, ainda, que o sujeito aprende na interação com o outro (GIORDAN, 1989, 1996; COELHO, 2000, 2008; MORAES, 2000). Existe um consenso, entre esses autores, de que ser um professor construtivista significa supor a construção do conhecimento facilitada pela interação com o meio físico e social.

A consideração dos conhecimentos prévios dos alunos e de suas experiências, pelo professor, é uma estratégia importante por favorecer o estabelecimento de relações entre os saberes já existentes e o que está sendo aprendido e ensinado. $\mathrm{Na}$ medida em que o professor investiga e leva em conta esses saberes, para conhecer melhor o aluno, suas necessidades e sua realidade, dispõe de novas ferramentas para criar situações que favoreçam a aprendizagem.

Segundo Astolfi (2001):

[...] é preciso que o mestre se adapte ao aluno, se faça epistemólogo de sua inteligência, estando atento às eventualidades de sua história pessoal; e é precisamente porque o mestre terá gasto tempo para isso que ele estará à altura de confrontar o aluno com a alternidade, de ajudá-lo a se superar. Todo aluno tem necessidade, ao mesmo tempo, de uma pedagogia que corresponda a ele e de se medir com outras pedagogias [...] (p. 87).

Inúmeras pesquisas realizadas na área do ensino de Ciências (ASTOLFI, 1988, 1998, 2001; COELHO, 2000; GIORDAN, 1989, 1996; GIL PÉREZ, 1983, 1988) têm sido justificadas pela necessidade de compreender e interpretar os processos pelos quais o aluno constrói seus conhecimentos científicos, bem como 
entender qual a participação e o papel de seus conhecimentos prévios nessas construções.

Segundo Astolfi (2001, p. 35), “[...] toda aprendizagem vem interferir com um "já existente" conceitual que, ainda que falso no plano científico, serve de sistema de explicação eficaz e funcional para o docente."

Nesse mesmo sentido, Giordan (1989) refere-se às representações e à aprendizagem significativa:

Por una parte las representaciones de los individuos no responden únicamente a imágenes de la realidad, también sirven como instrumento epistemológico (de pensamiento), como punto de anclaje para apropriarse de conocimiento, y por tanto constituyen estructuras de acogida que permiten interpolar nuevas informaciones. Juegan un papel de intermediario entre el conocimiento y el propio individuo y mediante una interacción entre estas estructuras de pensamiento y las informaciones que recibe el sujeto se produce un aprendizaje significativo (p. 59).

O autor pressupõe possibilidades de progresso do conhecimento do sujeito, partindo do seu conhecimento da realidade próxima para construir, num processo caracterizado por avanços e retrocessos, o conhecimento científico.

Da mesma forma, Solé (2006) refere-se à importância de considerar o conhecimento prévio do aluno:

Partir daquilo que o aluno possui, potencializá-lo e conotá-lo positivamente é sinal de respeito por sua contribuição, o que, sem dúvida, favorece sua auto-estima. Colocar desafios ao seu alcance, observar uma distância ótima entre o que traz e o que lhe é colocado incentivam seu interesse e lhe permitem confiar em suas próprias possibilidades; proporcionar-lhe as ajudas necessárias possibilita forjar uma imagem positiva e ajustada (p. 53).

Com base nesses pressupostos, as atividades desenvolvidas tiveram por objetivo trabalhar os seguintes conceitos e noções: circuito elétrico simples, circuito aberto e fechado, a função dos diferentes elementos de um circuito, a noção de isolantes e condutores, a caracterização das associações em série e paralelo e a explicação física dos fenômenos considerando o conceito de energia.

A abordagem metodológica da investigação foi qualitativa, tendo-se utilizado a técnica da observação participante, cuja importância, segundo Minayo (1993), reside no fato de: 
[...] captar uma variedade de situações ou fenômenos que não são obtidos por meio de perguntas, uma vez que, observados diretamente na própria realidade, transmitem o que há de mais imponderável e evasivo na vida real (p. 59).

Os dados foram obtidos por meio de filmagens, fotos, gravações das manifestações orais e produção escrita dos alunos, além da observação direta realizada pelos envolvidos na pesquisa.

Participaram, como sujeitos da investigação, sete alunos de escolas particulares de Porto Alegre, sendo três integrantes do Programa Educação de Jovens e Adultos (EJA), cursando a oitava série do Ensino Fundamental, e quatro do primeiro ano do Ensino Médio.

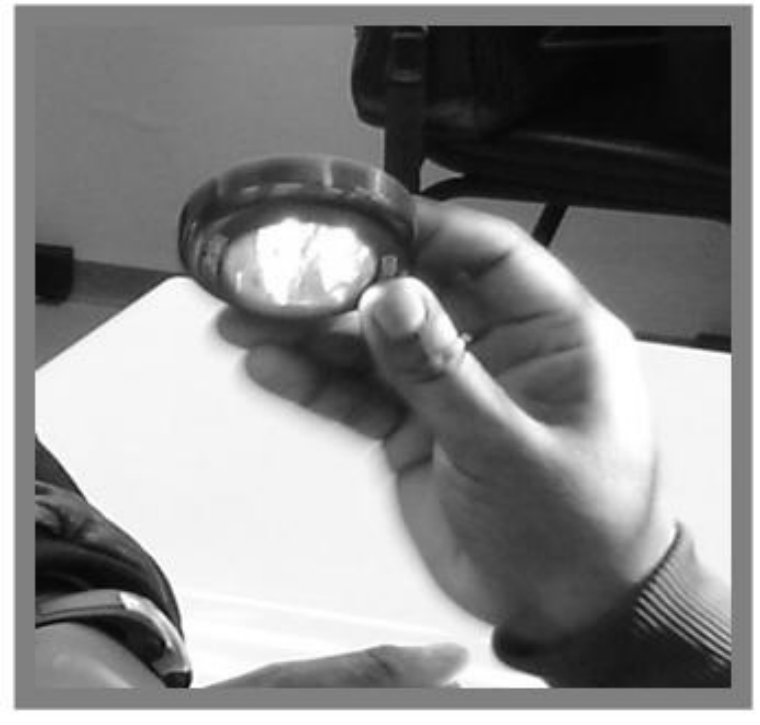

Fig. 2 - Lanterna não convencional investigada pelos sujeitos da pesquisa.

As atividades foram realizadas em dois encontros, totalizando oito horas.

Explorou-se a dimensão coletiva, permitindo-se a interação no pequeno e no grande grupo, possibilitando-se aos alunos manifestarem suas compreensões dos assuntos trabalhados, orientados pelos professores-pesquisadores e pela professora coordenadora.

No primeiro encontro, propôs-se, inicialmente, que os alunos investigassem o funcionamento de uma lanterna não convencional (Fig. 2), possibilitando-lhes a elaboração de um elenco de hipóteses e cabendo, ao pesquisador, um atento olhar para realizar o questionamento necessário, conduzir o processo e orientar, mediando a aprendizagem e identificando, dessa forma, o conhecimento prévio dos alunos. Nessa fase, a investigação da lanterna constituiu um fator motivador, cabendo ao aluno descrever o funcionamento da mesma, sua utilidade, expondo suas ideias e suas vivências quotidianas. 
Em sequência, foi sugerida aos alunos a construção de um circuito, com uma lâmpada, fios e uma pilha, para que investigassem seu funcionamento e compreendessem o circuito elétrico de uma lanterna. Toda construção realizada era registrada na forma de desenhos e por escrito, incluindo tanto as montagens bem sucedidas quanto as que não deram certo. Esses registros e os resultados obtidos nos pequenos grupos foram socializados no grande grupo, possibilitando-se a discussão e a confrontação das ideias.

No segundo encontro, os alunos apresentaram os esquemas dos circuitos montados, com discussões para compartilhar os saberes e favorecer a construção dos conceitos científicos, a partir da exploração do conhecimento prévio explicitado. Finalmente, houve montagem de circuitos com interruptores e várias lâmpadas para a investigação de circuitos em série e em paralelo, novamente com registro por meio de desenhos e explicações escritas.

A construção do projeto exigiu posicionamentos da mestranda, na negociação, com os estudantes da graduação, de vários aspectos, como a escolha da temática, a metodologia e organização da sequência de ensino, a abordagem metodológica da pesquisa, bem como os instrumentos de coleta e os processos de análise de dados. Como pesquisadora, aprendeu a criar situações para colocar em evidência os conhecimentos prévios dos alunos e, como professora, aprendeu a como se servir desses conhecimentos para auxiliá-los no processo de elaboração dos conhecimentos científicos.

\section{II.2 Analisando e interpretando resultados}

Utilizou-se a técnica da análise de conteúdo (MORAES, 1999; FRANCO, 2008), com base nas produções escritas e orais dos sujeitos. Dessa forma, foi analisado como, num contexto investigativo, comportavam-se e aplicavam seus conhecimentos prévios nas situações propostas. Essa análise resultou em duas categorias, apresentadas a seguir.

\section{II.2.1. Identificação dos elementos de um circuito elétrico facilitada por rela- ções estabelecidas entre o funcionamento de uma lanterna e vivências do quo- tidiano}

A atividade investigativa proposta gerou discussão no grupo, servindo para problematizar, inicialmente, o assunto em estudo. Os alunos especularam acerca do funcionamento da lanterna, conforme ilustram os extratos abaixo:

Sujeito A - Deve ser pra dentista que faz trabalho comunitário [...] 
Mestranda - Mas como é que vocês imaginam que seja esse aparelho?

Sujeito A - Ou também pode ser usado em laboratório de revelar fotos ou em raio- $X[\ldots]$

Professora - Como é que funciona?

Sujeito B - Tipo dentista é alguma coisa que tá reagindo aí tem uma cor diferente $[. .$.

Observa-se que, nessa situação, os sujeitos apresentaram dificuldades para responder à questão formulada "Como funciona a lanterna?", atendo-se às características visuais do objeto observado. Baseando-se em suas vivências, investigaram as estruturas do aparelho que manipulavam, no intuito de compreender seu funcionamento. Dando continuidade a suas especulações, avançaram tentando identificar os diferentes elementos que compunham o objeto e sua função.

Professora -E por que acende? Por que tu achas que acende?

Sujeito A - Acende porque deve ter um mecanismo tipo campainha..

Sujeito B - Bateria, bateria de relógio...

Sujeito A - Deve ser bateria ou pilha!

Sujeito $\mathrm{C}$ - Acho que é algum tipo de contato... se tu faz um contato leve ele não segura, daí acende e apaga... [...]

Professora - Por que tu achas que tem que tocar?

Sujeito B - Tem um contato, uns fiozinho assim, eu vivo desmontando as campainhas..

Sujeito B $-\dot{E}$... [...] só mantém o contato quando encosta um no outro, que nem o disjuntor lá do chuveiro, [...]

Professora - Falaste em interruptor? Em disjuntor, não foi?

Sujeito B - [...] não sei o nome científico da pecinha que faz os contatos, $[\cdots]$

Destaca-se a importância da problematização inicial no processo investigativo, pois possibilitou aos alunos o estabelecimento de relações entre o objeto em estudo e suas vivências.

II.2.2 Explicações iniciais, construção e aprofundamento de noções e conceitos a partir das ideias prévias

Ao pesquisador, coube estimular os alunos a expressarem suas ideias, seus conhecimentos, iniciando-se a elaboração de explicações a respeito do funcionamento do objeto em estudo. Segundo Giordan (1996), toda a 
aprendizagem vem interferir com um já existente conceitual, a aquisição do saber conceitual ocorrendo, assim, de forma progressiva, o que foi observado nessa experiência. Os alunos motivaram-se no decorrer dos debates, o que pode ser observado em seus questionamentos e reflexões:

Professora - Dá o contato, então tu achas que quando aperta com a mão dá o contato?

Sujeito A - Dá o contato.

Professora - Quer dizer quando tu apertas ... o que tu achas que aconte$c e ?[\ldots]$

Sujeito A - Ele tem um mecanismo dele que ele encosta. Dá o contato.

Professora-Quer dizer quando aperta com a mão dá o contato?

Sujeito $\mathrm{C}-$ Fecha corrente.

Sujeito A - É como um interruptor da lâmpada. Tu apertou, ligou. Tipo aquelas lâmpadas de hotel [...]

Sujeito B - É o mesmo que gira a lanterna [...] corre pra frente de metal em metal para ocorrer tem que ter um metal, que conduz energia.

Percebe-se a relevância, nesse tipo de metodologia, do problema inicialmente levantado, o qual passa a participar do contexto das atividades investigativas dos alunos, influenciando o processo de compreensão dos conceitos científicos.

Sujeito $\mathrm{C}-\mathrm{Eu}$ acho que tem um contato nas três lâmpadas e um mecanismo que quando fecha o circuito ai passa corrente elétrica e faz com que as lâmpadas acendam. Quando aperta faz o contato.

Mestranda - $O$ que tu achas que tem para acender essas lâmpadas? Só este contato?

Sujeito C - Não, tem matérias que conduzem energia e uma bateria, uma coisa que conduz energia.

Sujeito A - Primeiro possui lâmpadas e para acender tem que ter energia uma pilha uma bateria, ou até um fusivel. Uma fonte tem que ter para acender as lâmpadas. Essa é a grande base da coisa.

Discussões e reflexões promovidas nos grupos favoreceram a construção das noções de circuito, circuito aberto e circuito fechado. No processo de elaboração de hipóteses, explicações e questionamentos, contribuíram ainda as representações gráficas dos circuitos montados, por permitirem a análise dos acertos e dos erros cometidos. 
Outros conceitos aparecem no decorrer das atividades, como energia, tipos de energia, condutores e isolantes, mostrando que atividades investigativas em sala de aula suscitam aprendizagens que extrapolam a linearidade e os limites estabelecidos pelos programas disciplinares.

Professora - Vocês falaram de energia, que passa corrente. Vamos identificar cada componente. Para que serve a pilha?

Sujeito A - A pilha faz energia no caso. Os fios são condutores.

Professora - Condutores do quê? E a lâmpada?

Sujeito A - A lâmpada recebe energia. [...]

Professora - Que energia é essa que tem na pilha e na lâmpada? Qual é a energia que tem na lâmpada? [...]

Sujeito A - Elétrica. [...]

Professora - Quais são as energias que estão em jogo aí?

Professora-Foi identificado algum outro tipo de energia sem ser a elétri$c a ?$

Professora - Na lâmpada, por exemplo, que tipo de energia aparece?

Sujeito A - A luz.

Professora - Que mais, na lâmpada? O calor, não é? Energia térmica, não é? Esquenta não é? Existem várias energias ai... Interessante a identificação destas energias que estão aparecendo ai... Energia térmica, a luz.

Professora - E na pilha, o que tem dentro da pilha, vocês têm ideia?

Sujeito B - Energia.

Professora- Então? Essa energia que tem na pilha, que contém substâncias, a gente chama de energia química, não é? Estão ocorrendo diversas reações químicas ali, não é?

Professora- [...] Então pra gente poder pensar agora o que é a pilha? Qual a função da pilha? Qual a função da lâmpada? O que acontece na lâmpada? [...] De onde vem a energia elétrica, então?

Sujeito A - Da reação química. [...]

Professora - [...]E o condutor? Qual é a principal função dele?

Sujeito A - Conduzir energia.

Professora - Conduzir a energia! Que vocês acham? O fio conduz a energia? $[\ldots]$

Professora - Essa montagem para a lâmpada funcionar, como se chama? $[\ldots]$

Sujeito A - É o circuito não é?

Professora - Tudo isso é o circuito. O que é o circuito então? 
Nesse contexto, conceitos e noções como os de energia, transformação da energia, curto-circuito, potência, resistência elétrica, circuito aberto e fechado foram trabalhados no decorrer das atividades investigativas.

Por meio da problematização e da contextualização do conteúdo proposto, o conhecimento prévio do aluno serviu de âncora na formulação de conceitos científicos.

A experimentação, numa perspectiva investigativa, exerceu seu papel para auxiliar o aluno na construção do conhecimento científico, levando$\mathrm{o}$ à interpretação e à compreensão dos fenômenos físicos.

A situação de curto-circuito (lâmpada apagada) foi considerada, por alguns alunos, como equivalente à de um circuito aberto, concepção não aceita por outros componentes do grupo

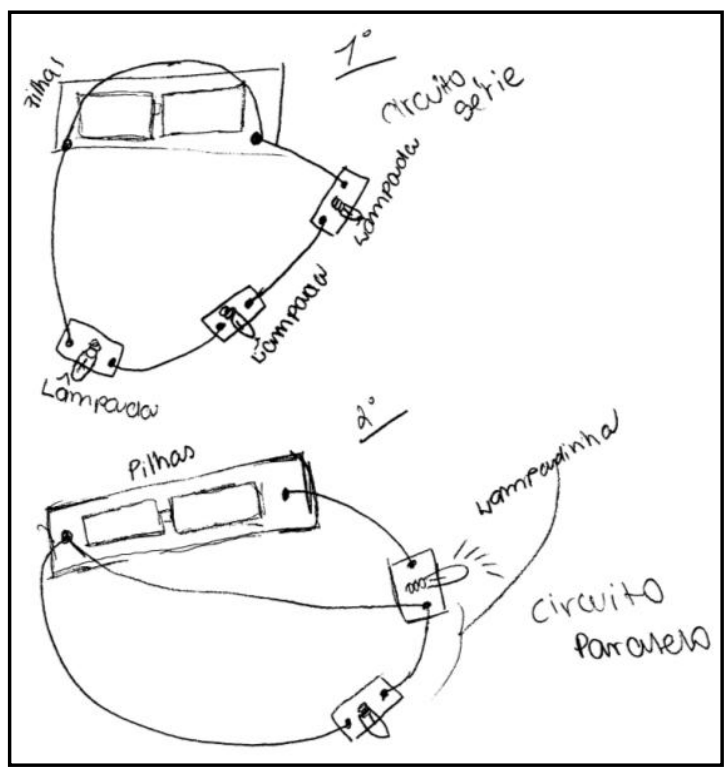
(Fig. 3):

Fig. 3 - Exemplo de representação de curtos-circuitos realizada por alunos durante as atividades experimentais.

Graduando - O que é corrente elétrica?

Sujeito $\mathrm{C}-\dot{E}$ onde passa eletricidade tem materiais que conduzem energia, quando corta tu termina com o contato, não fecha o circuito elétrico. [...]

Graduando - E se for um circuito aberto tem como passar?

Sujeito C - Não, está interrompido.

Sujeito B - Passa, ele tem como passar, só que...

Graduando - Ele, aberto, como faz para ele passar?

Sujeito B - Aqui através de fios, no caso aqui vai estar aberto ele vai vir de algum lugar e vai para outro, tem...

Graduando - Tem um fio e mesmo assim ele está aberto? 
Sujeito B - Sim.

Graduando - O que você estão chamando de aberto? Não sei se você está chamando a mesma coisa que ela?

Sujeito C - Para mim é um circuito, se não fechar circuito não tem como passar corrente elétrica.

Graduando - Então quando tu diz que ele está aberto, o que tu imaginas na tua mente. [...].

Sujeito C - Para mim é fechado quando passa energia e aberto é quando tu desencosta esse contato. Exemplo: vamos supor que tu tem uma placa metálica aqui no meio tu precisa de um outro condutor que encosta ai para fechar o circuito.

As dificuldades foram discutidas no grande grupo, favorecendo a confrontação de ideias e propiciando o esclarecimento de dúvidas com relação às noções de circuito aberto e fechado.

A atividade prática-investigativa proporcionou a utilização do conhecimento do cotidiano dos alunos, suas vivências e aprendizagens anteriores para construir conceitos mais condizentes com o conhecimento científico.

O extrato abaixo ilustra como foi possível abordar as noções de isolantes e condutores:

Professora - Quer fazer funcionar usando o lápis! [...], usar lâmpada, fio, pilha, lápis.

Professora - E a borracha?

Sujeito B - A borracha não. [...].

Sujeito B - [...], porque a borracha não conduz energia.

Professora - Mas o que tem o lápis então?[...] a madeira?

Sujeito B - A madeira não conduz, mas a grafite sim.

É interessante salientar que o fato de ter-se permitido aos alunos a realização de experimentos (Fig. 4) não previstos no planejamento, levando em conta seus conhecimentos prévios e suas hipóteses, estimulou-os a testar e identificar materiais isolantes e condutores. Esse momento de aprendizagem foi significativo pelo fato de o sujeito ter associado a situação atual a um fato ocorrido em seu dia-a-dia, ou seja, um choque que teria levado ao ter colocado um lápis numa tomada de $220 \mathrm{~V}$.

Muitas vezes, o conteúdo ensinado está presente no quotidiano, mas dificilmente é relacionado aos conhecimentos prévios dos alunos, no contexto 
escolar. A maioria desconhece a importância do que aprende, reproduzindo apenas o necessário para aprovação.

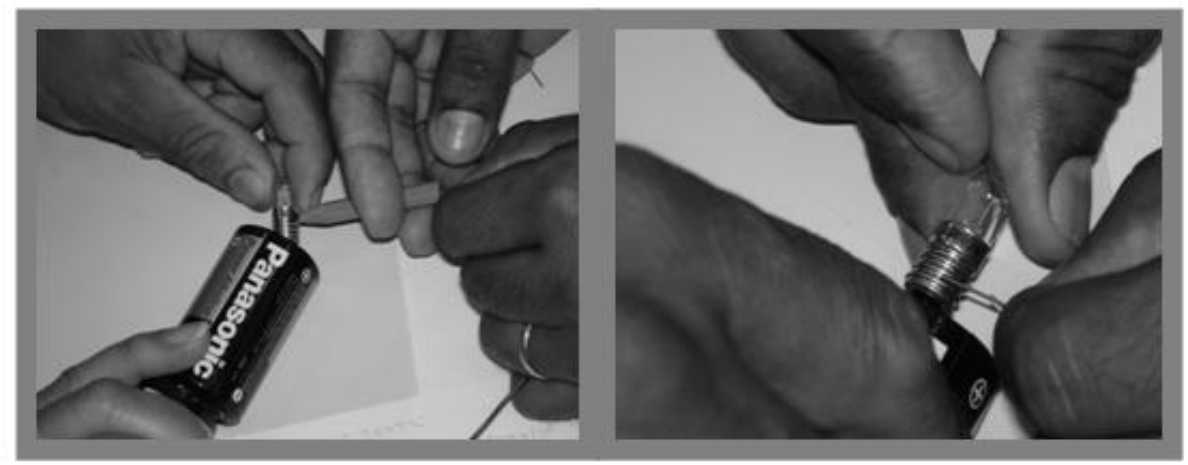

Fig. 4 - Uso do grafite para testar sua condutividade elétrica.

A atividade investigativa dos alunos permitiu que diversas habilidades fossem trabalhadas, como as capacidades de comunicação, de expressão oral, de observação, de análise (na identificação de erros e acertos), de formulação de hipóteses e ainda de seleção de procedimentos experimentais. A proposta metodológica contribuiu para o desenvolvimento cognitivo dos sujeitos, possibilitando-lhes uma participação ativa, ao serem autores de sua própria aprendizagem, construindo seu conhecimento científico com base em suas experiências e seus conhecimentos prévios.

A observação da pesquisadora durante a coleta de dados serviu para a compreensão das atividades cognitivas de elaboração conceitual e da forma como ocorrem as relações entre a teoria e a prática nos processos de aplicação e integração dos conhecimentos teóricos no plano experimental.

Formulações inicialmente incipientes e pouco argumentadas deram origem a conceitualizações mais estruturadas e complexas, graças ao espaço criado para realização de reflexões e questionamentos. $\mathrm{O}$ olhar atento $\mathrm{e}$ acompanhamento desse processo de estruturação conceitual permitiram à mestranda dar um novo significado à importância da elaboração própria no processo de ensino e aprendizagem mediado pelo professor. 


\section{II.2.3 Percepção dos alunos sobre sua aprendizagem}

A pesquisadora buscou avaliar o modo como os alunos interpretaram essa experiência de ensino e aprendizagem, utilizando o seguinte questionário:

1. O que você pensa a respeito da aprendizagem de Ciências (Física) baseada na pesquisa por meio da experimentação?

2. Quanto à aprendizagem de conceitos, o que foi possível aprender?

3. Que aspectos positivos ou negativos você registrou? Dê sugestões.

Foram elaboradas três categorias de análise a partir das respostas a essas perguntas, as quais são apresentadas a seguir, com alguns exemplos de extratos ilustrativos.

\section{- A importância da relação entre a teoria e a prática}

A análise dessas respostas indica que os sujeitos perceberam a importância da relação entre a teoria e a prática em sua aprendizagem, confrontando a metodologia proposta à clássica do aprender recorrendo apenas à memória. Além disso, o experimento é valorizado, por permitir-lhes confrontar suas hipóteses com os resultados experimentais, falseando, muitas vezes, ideias prévias equivocadas. Os extratos abaixo ilustram essa categoria da análise:

Sujeito A - "Acho que a aprendizagem só de conceitos é mais monótona, requer muito mais da memória e da imaginação para poder captar tudo que é ensinado, portanto se a aula for composta de teoria e prática chegaremos muito mais rápido aos resultados, e de forma muito mais completa podemos ter a noção exata sobre aquilo que estamos estudando."

Sujeito C - "Podemos percebê-los somente quando vamos utilizar os conceitos na prática ou em experimentos, dai é que percebemos os conceitos na prática ou em experimentos dai é que percebemos o quão importantes são os conceitos e pra que servem”.

Sujeito C - "Sim, houve porque tudo aquilo que eu sabia pude de alguma forma compreender melhor e utilizar corretamente ou às vezes tentar para ver no que dá, se está correto ou não o que eu sabia”.

\section{- Importância de aspectos relacionados a processos de aprendizagem}

Alguns sujeitos mencionam aspectos que relacionam processos de aprendizagem, como o desenvolvimento de seu senso crítico e de sua capacidade de 
raciocínio, referindo-se também à possibilidade de evolução no plano conceitual em termos de complexidade e de maior aproximação ao saber científico:

Sujeito B - "Ao meu modo devemos estimular e aprimorar esses conceitos de aprendizados, pois aumenta o censo crítico a área de debates e amplia mais os conceitos para acusar a capacidade de raciocino dentro de um trabalho democrático em busca do conhecimento".

Outros aspectos, também mencionados na avaliação, referem-se à importância da escuta e da oportunidade oferecida para o pensamento divergente e o exercício da livre expressão oral:

Sujeito B - Achei super válido pois intensifica a livre opções de opiniões, usando materiais para o aprendizado não somente só teoria mas se trabalhando e debatendo em cima da prática e adquirindo conhecimentos no manuseio e na oportunidade de fazer aprendendo.

\section{- Aspectos atitudinais, como a motivação, curiosidade etc.}

A metodologia proposta foi considerada motivadora, favorecendo atitudes como a curiosidade e o interesse dos alunos:

Sujeito A - Eu acho que a aprendizagem de ciências (física) baseada na pesquisa, muito mais interessante, pois desperta nossa curiosidade, fazendo com que quanto mais descobrimos, mais resultados queremos buscar. Encontrei maior facilidade de compreensão, as tarefas são realizadas com mais prazer e interesse.

Os sujeitos da pesquisa consideraram importantes as formas como o conteúdo foi desenvolvido e, também, como ocorreu a aprendizagem, os conceitos adquirindo um significado próprio, construído a partir de seus conhecimentos prévios.

A obtenção desses resultados exigiu da mestranda a realização da análise de conteúdo, tendo, para isso, que buscar conhecimentos na área de metodologia da pesquisa, aprofundando-se na técnica de elaboração de categorias, aprendendo, assim, a interpretar e a extrair novas informações dos dados coletados.

\section{Considerações finais}

Essa experiência de iniciação à pesquisa proporcionou situações de aprendizagens, nos contextos de sala de aula e acadêmico, gerando oportunidades para compartilhar saberes em discussões com colegas e com a professora orientadora, 
num processo reflexivo sobre o ensinar e o aprender, levando em conta os conhecimentos prévios dos alunos.

Reflexão e visão crítica sobre os processos de ensino e aprendizagem na prática docente exigem envolvimento e um contínuo estudar por parte do professor. A prática escolar embasada nessa concepção é um caminho a ser vislumbrado, instigando as capacidades de criação do professor e oferecendo ao aluno condições para desenvolver-se enquanto cidadão. Por um lado, o professor orienta, mediando e mantendo um olhar atento que acompanha e compreende; por outro lado, o aluno, desafiado, cria, recria e constrói seus conhecimentos, a partir de suas experiências.

O professor desenvolve, com a prática da pesquisa, a capacidade de argumentação, seus conhecimentos teóricos e práticos, abrangendo o saber e saberfazer.

A prática da pesquisa permitiu uma tomada de consciência acerca do importante papel do professor como agente no processo de criação de um espaço para questionamentos, argumentação, investigação e momentos para aprendizagem a partir dos próprios erros. Também fez com que a pesquisadora trocasse experiências com os alunos e refletisse sobre seu papel como educadora, bem como aprendesse a valorizar os saberes dos educandos para a construção de seus conhecimentos.

Aprendizagens referentes à iniciação à prática da pesquisa em disciplinas de cursos de formação de professores constituem ferramentas imprescindíveis para a construção de uma visão crítica e o exercício de um olhar atento com relação ao conhecimento prévio dos alunos, a suas dificuldades e reações, aos materiais instrucionais e aos processos de ensino e aprendizagem. Em nível de cursos de Programas de Pós-Graduação em Educação em Ciências, repercutem na formação de professores, não somente no que se refere à prática docente, mas também na própria construção e realização do projeto de dissertação de mestrado. O professorpesquisador adquire, assim, melhores condições e habilidades para escolher e aplicar métodos e instrumentos de coleta e análise de dados em atividades de pesquisa.

\section{Agradecimentos}

Aos árbitros, pelas sugestões, ao professor António Dias Nunes, a Anderson Jackle e a Cristiane Rodrigues de Rodrigues, integrantes do Grupo de Pesquisa em Didática das Ciências, pela revisão final do texto. 


\section{Referências}

ASTOLFI, J. P. El aprendizaje de conceptos científicos: aspectos epistemológicos, cognitivos y linguísticos. Enseñanza de las Ciencias, Barcelona, v. 6, n. 2. p. 147$155,1988$.

ASTOLFI, J. P. Desarrolar um currículo multirrefenciado para hacer frente a la complejidad de los aprendizajes científicos. Enseñanza de las Ciencias, Barcelona, v. 16, n. 3, p. 375-385, 1998.

ASTOLFI, J. P.; DEVELAY, M. A Didática das Ciências. 6. ed. Campinas: Papirus, 2001.

ARCÁ, M.; GUIDONI, P. Modelos infantiles y modelos científicos sobre la morfogia de los seres vivos. Enseñanza de las Ciencias, v. 7, n. 2, p. 162-167, 1989.

BACHELARD, G. A formação do espírito científico. São Paulo: Contraponto, 1996.

COELHO, M. S. Referências bibliográficas organizadas em didática das ciências. Caderno Catarinense de Ensino de Física, Florianópolis, v. 8, n. 3, p. 181-192, 1991.

COELHO, S. M. et al. Conceitos, atitudes de investigação e metodologia experimental como subsidio ao planejamento de objetivos e estratégias de ensino. Caderno Catarinense de Ensino de Física, Florianópolis, v. 17, n. 2, p. 122-149, 2000.

COELHO, S. M. et al. Formação Continuada, Pesquisa e Ensino de Ciências. In: REUNIÓN INTERNACIONAL SOBRE LA ENSEÑANZA DE LA FÍSICA Y LA ESPECIALIZACIÓN DE PROFESORES, 2005, Matanzas. Actas... Matanzas: RIEFEP, 2005. (CD-ROM).

COELHO, S. M.; NUNES, A. D.; WIEHE, L. C. N. Formação Continuada de Professores numa Visão Construtivista: contextos didáticos, estratégias e formas de aprendizagem no ensino experimental de Física. Caderno Brasileiro de Ensino de Física, v. 25, n. 1, p.7-34, 2008.

COELHO, S. M.; TIMM, R. M. B.; SANTOS, J. M. Formação de professorpesquisador: a importância da prática dos processos de coleta e de análise de dados na iniciação à pesquisa. In: SIMPÓSIO NACIONAL DE ENSINO DE FÍSICA, 
XVIII, 2009, Espírito Santo. Trabalho apresentado como comunicação oral. Disponível em:

$<$ http://www.sbf1.sbfisica.org.br/eventos/snef/xviii/sys/resumos/T0675-1.pdf> Acesso em: 13 de maio de 2010.

DEMO, P. Educar pela pesquisa. 7. ed. Campinas: Autores Associados, 2005.

DEMO, P. Pesquisa: principio cientifico e educativo. 11. ed. São Paulo: Cortez, 2005 .

FRANCO, M. L. P. B. Análise de Conteúdo. 3. ed. Brasília: Liber Livro, 2008.

GIORDAN, A. As origens do saber: das concepções dos aprendentes aos conceitos científicos. 2. ed. Porto Alegre: Artes Médicas, 1996.

GIORDAN, A. Representaciones sobre la utilización didática de las representaciones. Enseñanza de las Ciencias, Barcelona, v. 7, n. 1, p. 53-62, 1989.

HALBWACHS, F. La Fisica del profesor entre la Fisica del físico y la Física del alumno. Enseñanza de la Física, Argentina, v. 1, n. 1, p. 19-29, 1975.

LEITE, M. A. Formação docente: ciências e biologia: estudo de caso. Bauru: EDUSC, 2004.

MINAYO, M. C. S. (Org). Pesquisa social: teoria, método e criatividade. 23. ed. Petrópolis: Vozes, 1994.

MORAES, R. É possível ser construtivista no Ensino de Ciências? In: MORAES, R. (Org). Construtivismo em ensino de Ciências. Porto Alegre: EDIPUCRS, 2000. p. 103-30.

MORAES, R.; GALIAZZI, M. do C. Análise textual discursiva. Ijuí: Unijuí, 2007.

MORAES, R.; LIMA, V. M. do R. (Orgs). Pesquisa em sala de aula: tendências para a educação em novos tempos. 2. ed. Porto Alegre: EDIPUCRS, 2004.

PAIS, L. C. Didática da Matemática: Uma análise da influência francesa. Belo Horizonte: Autêntica, 2001.

PEREZ, D. G. Três paradigmas básicos en la enseñanza de las ciencias. Enseñanza de las Ciencias, v. 1, n. 1, p. 26-33, 1983. 
PEREZ, D. G.; TORREGROSA, M. J.; PEREZ, S. F. El fracasso en la resolución de problemas de Física: una investigación orientada por nuevos supuestos, Enseñanza de las Ciencias, v. 6, n. 2, p. 131-146, 1988.

POLITY, E. Ensinando a ensinar. São Paulo: Lemos Editorial, 1997.

SÉRÉ, M. G.; COELHO, S. M.; NUNES, A. D. O papel da experimentação no ensino da Física. Caderno Brasileiro de Ensino de Física, v. 20, n. 1, p. 30-42, 2003.

SOLÉ, I. Disponibilidade para a aprendizagem e sentido da aprendizagem. In: COLL, E. C. (Org). O construtivismo na sala de aula. São Paulo: Ática, 2006. 